\title{
GLOBALIZACIÓN, NEOLIBERALISMO Y SISTEMAS DE SALUD
}

\section{GLOBALIZATION, NEOLIBERALISM AND HEALTH SYSTEMS}

\section{Jenni Andrea Ibarra Carbajal ${ }^{1}$ Ruslan Posadas Velázquez ${ }^{2}$}

Me pregunto qué negocio es éste, en que hasta el deseo es un consumo. ¿Qué me haré cuando facture el sol? Silvio Rodríguez

\section{Resumen}

En este artículo se abordan los cambios que han experimentado los sistemas de salud en el contexto de las transformaciones radicales que han tenido lugar en la vida sociopolítica y socioeconómica de los Estados a partir de la entrada en escena del actual proceso de globalización en su vertiente neoliberal, destacando, de manera particular, algunos elementos para comprender el caso mexicano.

Palabras-clave: Globalización; Sistemas de Salud; Neoliberalismo.

\section{Abstract}

This article addresses the changes that the health systems have undergone in the context of the radical transformations that have taken place in the socio-political and socio-economic life of the States, starting from the stage of the current process of globalization in its neoliberal aspect, highlighting, in particular, some elements to understand the Mexican case.

Keywords: Globalization; Health Systems; Neoliberalism.

\footnotetext{
${ }^{1}$ Doctora en Ciencias Políticas y Sociales por la UNAM, especialista en el sistema de salud mexicano y con amplia experiencia en la administración pública federal. E-mail: jenni.carbajal@unam.edu.mx

2 Doctor en Ciencias Políticas y Sociales por la UNAM y Profesor Investigador de la Academia de Ciencia Política y Administración Urbana de la Universidad Autónoma de la Ciudad de México (UACM) y Profesor de Asignatura en el Centro de Estudios en Administración Pública de la Facultad de Ciencias Políticas y Sociales de la UNAM. E-mail: ruslan.posadas@uacm.edu.mx
} 


\section{EL TEMA Y EL ANATEMA}

La fisonomía que adquieren los sistemas de salud no responde únicamente a las necesidades relacionadas con la materialidad biomédica de los individuos o al perfil epidemiológico de las colectividades, atiende también a variables de índole política, económica y cultural puesto que los sistemas sanitarios no son entes que se desarrollen de manera aislada o ajena a un contexto social determinado.

En este sentido, el origen y transformación de los sistemas de salud se ve íntimamente ligado a ciertos procesos históricos y, por tanto, la naturaleza de dichos sistemas, a su vez, refleja con buen grado de nitidez las características de la organización social que los confecciona.

En las postrimerías del siglo XX y los albores del XXI, el mundo ha experimentado una oleada de cambios sin precedente, vinculados indiscutiblemente a los vertiginosos avances tecnológicos, que han transfigurado el rostro de lo que solíamos denominar modernidad, así como de los paradigmas y patrones derivados de ella.

Contrario a la idea de que el progreso de la ciencia y la tecnología nos conducirían a una sociedad cada vez más estable, ordenada, segura y predecible, en la actualidad nos encontramos en presencia de "un mundo desbocado", como diría Anthony Giddens, en el que el riesgo y la incertidumbre son las constantes de una fenomenología social permeada por la globalización.

La globalización ha trastocado estructuras fundamentales de la sociedad y ha renovado la naturaleza misma del poder. La globalización, en ese sentido, no puede considerarse como un fenómeno aislado es, pues, una serie compleja de procesos que operan de manera contradictoria o antitética, presionando hacia arriba, hacia abajo y hacia los lados, la globalización es económica, política y cultural, afecta a los grandes sistemas, pero influye también en los aspectos íntimos de la vida de los individuos (Giddens, 2008).

En las esferas política y económica, al conmover la naturaleza del poder, la globalización ha conducido a la edificación de un nuevo orden mundial en el que los Estados comparten con otros actores el papel protagónico de su historia.

Los gobiernos y la política, en tal contexto, gozan de un margen de maniobra cada vez menor, pues la actividad de los agentes económicos trasnacionales mina la soberanía y la autonomía estatal, al tiempo que la injerencia de los organismos financieros internacionales en la jurisdicción nacional circunscribe, cada vez con mayor precisión, su radio de acción en 
ámbitos otrora considerados esenciales para el bienestar de la colectividad y por lo tanto responsabilidad estatal.

En este marco, en el que las decisiones que afectan a las personas muy a menudo se toman fuera de los confines estatales y por lo tanto devienen en decisiones ajenas al ciudadano si no es que en ocasiones contrarias al mismo, es que se propone realizar un análisis sobre la reconfiguración del sector salud, a la luz de la recomposición de un orden mundial caracterizado por la globalización y la aparición y consolidación de actores que se han arrogado el papel de dirigir el "concierto de naciones".

\section{¿CÓMO EXPLICAR LA GLOBALIZACIÓN?}

Al hablar de globalización no es extraño que con frecuencia se recurra al uso de términos como interacción, interrelación, integración, interdependencia o incluso convergencia, palabras que evocan una suerte de sentido de proximidad entre individuos, grupos sociales, comunidades, países y regiones.

Con la globalización se percibe, a menudo, una sensación de que la variable espaciotiempo se ha visto alterada: las distancias se hacen cada vez más cortas y el tiempo transcurre cada vez más rápido (Bauman, 2001).

Se nos presentan, en este tenor, definiciones en las que se señala que la globalización denota la expansión a escala, a magnitud creciente, de un acelerado y profundo impacto de flujos transcontinentales y patrones de interacción social. Se apunta que la globalización se refiere al cambio o transformación a nivel de la organización humana que une comunidades distantes y amplía el alcance de las relaciones de poder entre regiones y continentes (Held y McGrew, 2002 en Gilbert, 2008:187).

Asimismo, se señala que la globalización se refiere a "la intensificación de las relaciones sociales en todo el mundo por las que se enlazan lugares lejanos, de tal manera que los acontecimientos locales están configurados por acontecimientos que ocurren a muchos kilómetros de distancia o viceversa" (Giddens, 2004: 67,68).

Esto se debe, en gran medida, a lo que suele denominarse la revolución tecnológica e informática:

"[...] que ha dado vida a una verdadera red mundial de conexiones espaciales y de interdependencias funcionales. Esta red pone en mutuo contacto a un número creciente de actores sociales y de acontecimientos económicos, políticos, culturales y comunicativos, que en un tiempo 
estaban desconectados a causa de las distancias geográficas o de barreras cognitivas y sociales de distinto tipo" (Zolo, 2006: 18,19).

En este sentido, no es de sorprender que, para muchos, sin la globalización, vista como un fenómeno irreversible e ineludible, no podría explicarse la transición de la humanidad hacia el siglo XXI. La globalización, se dice, se ha convertido en una especie de nuevo paradigma del mundo contemporáneo (Beck, 1998; Zolo, 2006; Giddens, 2008).

En este orden de ideas, la globalización percibida como entelequia de la modernidad usualmente es categorizada, a fin de favorecer la comprensión del alcance de su ámbito de influencia, en función de los distintos aspectos de la vida social a los que impacta, de tal manera que se suele caracterizar en económica, cultural y política.

En la esfera económica, la globalización se ha definido como "la aceleración y la intensificación del proceso de formación de una economía mundial que se está configurando como un sistema único, que funciona en tiempo real" y que "se identifica con los libres movimientos de capital y con el creciente dominio de los mercados financieros globales y de las empresas multinacionales sobre las economías nacionales" (Gallino, 2001; Soros, 2002 en Zolo, 2006: 22, 23).

Para las actividades económicas, desde esta perspectiva, ya no resulta un impedimento la distancia geográfica dado que, por un lado, las tecnologías de la información y la comunicación (TIC) las han dotado de un gran potencial de acción ${ }^{3}$ y, por otro, las grandes corporaciones actualmente pueden recurrir a la sub-contratación en regiones distantes operando, de esta manera, en un mundo sin fronteras. Las compañías trasnacionales son, en este sentido, actores primordiales en el proceso de globalización (Kiely, 2008).

Se podría afirmar, en este contexto, que se está en presencia de una suerte de "desfordización" de la economía, en el sentido de la exacerbada tendencia a que el lugar de producción (la periferia) cada vez empate menos con el lugar donde se localiza el destinatario final de dicha producción (el centro) dada la desaparición de la otrora codependencia entre el capital y la fuerza de trabajo ${ }^{4}$.

\footnotetext{
${ }^{3}$ Michel Albert señala que "Gracias a las computadoras, a los satélites [y] a los cables, los datos financieros pueden circular libremente a través del mundo y negociarse instantáneamente. La introducción de las nuevas tecnologías ha permitido disminuir en un $98 \%$ el costo de las transacciones", (Albert, 1997: 168).

${ }^{4}$ Para Zygmunt Bauman, la decisión tomada por Henry Ford de duplicar los salarios de sus trabajadores respondía a una consideración racional: "si bien sus trabajadores dependían de él para ganarse el sustento, él a su vez dependía de ellos, la mano de obra local, los únicos operarios que podía usar para mantener la línea de montaje en funcionamiento por el bien de su poder y su fortuna. La dependencia era mutua. [...] En contraste con sus descendientes de un siglo más tarde, el viejo Henry Ford no disponía
} 
Dentro del ámbito económico, la vertiente financiera además de mostrar desdén por las fronteras, enfatizará una lógica de mercado puro y duro, sin gendarmes: sin límites (Albert, 1997).

La formación de una economía de libre mercado mundial ha sido, no obstante, fuertemente cuestionada dado que, al contrario de promover un efecto distributivo global, el capital no ha roto su natural tendencia a la concentración en ciertas zonas del planeta, a la vez que otras, las más, siguen quedando al margen de ese proceso cumulativo.

Se dice, en este sentido, que dada la concentración global del capital, la desesperación de las economías nacionales por atraer inversión extranjera y la hegemonía neoliberal en el orden internacional, sería justo decir que la capacidad (o quizá la disposición) de los estados del mundo en desarrollo, para regular a las compañías (locales o extranjeras) de manera que se comporten en términos desarrollistas, se ve seriamente comprometida (Kiely, 2008).

La conformación de la "nueva división internacional del trabajo", 5 el consecuente incremento de "zonas de procesamiento para exportación" o de la industria manufacturera en el mundo en desarrollo, a pesar de lo que afirman los apologistas del mercado global, no ha reducido la brecha entre los países industrializados y los no industrializados (Desai, Potter, 2008; Kiely, 2008). ${ }^{6}$

Como lo plantea Zygmunt Bauman (2008: 14, 15), retomando cifras de Jacques Attali: "en sólo 22 países (en los que se acumula apenas el 14 por ciento de la población humana total) se concentra la mitad del comercio mundial y más de la mitad de las inversiones globales,

de la suprema "arma de la inseguridad", es decir, la opción de trasladar su riqueza a otros lugares: lugares repletos de gente dispuesta a soportar sin un quejido cualquier régimen fabril, incluso el más cruel, a cambio de cualquier paga, incluso la más miserable; al igual que sus trabajadores, el capital de Ford estaba "fijo" al lugar, sumergido en una pesada y voluminosa maquinaria, encerrado entre los altos muros de la fábrica. Ambas partes tenían plena conciencia de un secreto a voces: que su dependencia era mutua, por lo que estaban destinadas a permanecer juntas durante mucho tiempo por venir", (Bauman, 2011: 63).

5 "The so-called new international division of labour (NIDL) has to be seen as a vital aspect of globalization, pinpointing shifts in production by world region, and affecting both manufacturing and producer services. At least three NIDLs can be recognized: at the time of European colonization, the industrial development of certain semi-developed areas at the end of the nineteenth century, and the present era, in which foreign direct investment (FDI) has expanded greatly", (Desai V, Potter R, 2008: 181).

${ }^{6}$ Los apologistas del mercado global argumentan que las compañías transnacionales promueven el desarrollo de los países receptores dado que generan ingresos, empleo, tecnología, etc. y señalan que la producción de bajo costo y de trabajo intensivo es un requerimiento para los países pobres, y que escalar hacia una producción de mayor valor ocurrirá con el tiempo, justo como lo experimentaron los países desarrollados. El rápido crecimiento de China es un buen ejemplo que muestra claramente los beneficios de la globalización en contraste con las políticas cerradas de la época Maoista, se señala (Kiely, en Desai, Potter, 2008: 183,184). 
mientras que los 49 países más pobres (en los que habita el 11 por ciento de la población mundial) reciben en conjunto sólo el 0, 5 por ciento de la producción global, casi lo mismo que los ingresos de los tres hombres más ricos del planeta. El 90 por ciento de la riqueza total del planeta está en manos de sólo el uno por ciento de sus habitantes. Y no se distinguen en el horizonte escolleras que puedan detener la marea global de la polarización de las ganancias, que continúa creciendo de manera amenazadora".

Por su parte, Danilo Zolo (2006:52) afirma que "a comienzos de los años sesenta [del siglo pasado] el 20 por ciento más rico de la población mundial disponía de rentas 30 veces superiores a las del 20 por ciento más pobre [...] después de casi 40 años, el 20 por ciento más rico goza de unas rentas casi 66 veces superiores a las de la franja más pobre de la población mundial".

Es en este sentido que se señala que "la globalización y la localización no sólo son dos momentos o caras de la misma moneda; son al mismo tiempo fuerzas impulsoras y formas de expresión de una nueva polarización y estratificación de la población mundial en ricos globalizados y pobres localizados" (Beck, 1998: 88).

Respecto al ámbito cultural se dice que el creciente uso de los medios masivos de comunicación, así como el protagonismo adquirido por el libre mercado han generado la conformación de ciertos patrones que se han extendido a nivel global: Cada vez más consumimos los mismos productos y somos bombardeados con la misma clase de publicidad.

Se afirmará, en este sentido, que el sistema capitalista mundial ha logrado imponer, gracias a la globalización, estereotipos que marcan pautas de consumo y estilos de vida de corte occidental, promoviendo una creciente "convergencia cultural" a escala global. El proceso de globalización, se apunta, al trastocar o incluso romper con ciertos referentes conlleva a la homogeneización del mundo: a "la Mc Donalización de la sociedad" (Ritzer, 2004).

Desde esta perspectiva se señala que la "occidentalización" del mundo trae aparejada la pérdida de la diversidad y especificidad cultural, pues el mundo se vuelve con mayor rapidez, si no exactamente igual si cada vez más similar. Idea, cabe subrayar, no necesariamente nueva ya que, a principios de la segunda mitad del siglo pasado, la teoría de la modernización daba por sentado que el mundo progresivamente se "occidentalizaría" o más precisamente se “americanizaría" (Massey y Jess, 1995; Murray, 2006 en Potter, 2008).

Este planteamiento, stricto sensu, destacaba la probabilidad de la homogeneización cultural planetaria con rasgos norteamericanos dominantes de consumo, ejemplificados por la “Coca-colonización", la "Hollywoodización” o la "Miamización" del tercer mundo (Potter, 2008). 
En este contexto, para la convergencia global, en términos de las preferencias y hábitos de consumo, de particular importancia será el "efecto demostración" que involucra la rápida asimilación de los gustos y patrones de consumo estadounidenses y europeos (McElroy y Albuquerque, 1986 en Potter, 2008).

Gina Zabludovsky (2008: 38) señalará, en este tenor, que "en la medida en que los modelos de comportamiento no responden a un ámbito territorialmente delimitado, los gustos y tendencias mundiales son cada vez más uniformes y tenemos una agudización de lo que, desde los años sesenta, Herbert Marcuse concibió como una sociedad unidimensional".

Desde otra perspectiva se argumenta que, si bien es cierto que los símbolos de los estilos de vida y patrones de consumo occidentales, tales como Coca-Cola, Disney, McDonald's y Hollywood están al alcance de la mano, éstos iconos culturales mundiales son reinterpretados localmente, configurando diferentes significados en lugares distintos. En otras palabras, la localización y la fragmentación son vistas también como correlatos de la globalización (Cochrane, 1995 en Potter 2008; Beck, 1998).

Para Bauman (2001), los procesos globalizadores, asimismo, incluyen una segregación, separación y marginación social progresivas. Las tendencias neotribales y fundamentalistas ${ }^{7}$ que reflejan y articulan las vivencias de los beneficiarios de la globalización son hijos tan legítimos de ésta como la tan festejada 'hibridación de la cultura superior', es decir, la cultura de la cima globalizada.

Desde esta perspectiva se afirma que lejos de conducir a un mundo uniforme, la globalización está estrechamente vinculada a la perpetuación y exacerbación de las inequidades espaciales, recordemos que para Beck (1998) la globalización y la localización son formas de expresión de una nueva polarización y estratificación de la población mundial.

Así, podría afirmarse que a la "convergencia cultural", impulsada por "la mercadotecnia estandarizada" y el "consumismo global", corresponderá (en sentido inverso) la "divergencia social", alimentada por las disparidades en los patrones de producción y acumulación de capital características de la economía global.

Lejos de homogeneizar la condición humana, señalará Bauman (2001:28), la anulación tecnológica de la distancia de tiempo y espacio tiende a polarizarla. Emancipa a ciertos humanos de las restricciones territoriales a la vez que despoja al territorio, donde otros

\footnotetext{
7 Danilo Zolo utiliza el término pseudospeciazione "que se refiere a un fenómeno por el que grupos humanos muy diferenciados culturalmente se comportan recíprocamente como si fueran especies diferentes, en vez de pertenecer a la misma especie humana", Nota del traductor a la edición italiana, (Zolo, 2006: 69,70).
} 
permanecen confinados, de su valor y su capacidad para otorgar identidad. Para algunos augura una libertad sin precedentes de los obstáculos físicos y una inédita capacidad de desplazarse y actuar a distancia. Para otros, presagia la imposibilidad de apropiarse y domesticar la localidad de la cual tendrán escasas posibilidades de liberarse para ir a otra parte.

En lo que respecta a la esfera política, la globalización se refiere a los "procesos en virtud de los cuales los estados nacionales soberanos se entremezclan e imbrican mediante actores transnacionales y sus respectivas probabilidades de poder, orientaciones, identidades y entramados varios" (Beck, 1998: 29).

Esta mezcla y superposición es producto del avance de la internacionalización vista como precursora de la globalización (Potter, 2008 en Desai, Potter, 2008: 192) y entendida como la extensión geográfica de las actividades económicas a través de las fronteras nacionales, es decir, el libre comercio mundial (Beck, 1998; Jaramillo, 1998; Zabludovsky, 2008), lo que ha derivado, al parecer de no pocos, en la gradual pero constante erosión del poder y debilitamiento del papel del Estado-nación.

Así bajo un sistema crecientemente globalizado, los gobiernos se ven "obligados" a recurrir a circunscripciones extraterritoriales debiendo atender de tal manera a los intereses de los inversionistas extranjeros, así como de las instituciones financieras internacionales ya que ejercicios independientes de política económica como la inducción del crecimiento podrían provocar fuga de capitales, devaluación de la moneda e inflación (McNamara, 1998; Simmon, 1999; Goodman, 1992; Maxfield, 1997 en Babb, 2001: 4,5).

"La transferencia de una amplia parte del poder de decisión, no sólo en materia económica y financiera, a las fuerzas del mercado global y a los mayores protagonistas de la economía mundial, empezando por las más poderosas corporaciones económicas y financieras" (Zolo: 2006:30) ha desembocado en la decadencia o crisis del Estado-nación territorial (Held, 1997) o visto más dramáticamente en el final de esa organización política por antonomasia (Ohmae, 1997).

Si la "primera modernidad" se explica vinculada al origen del Estado social y su tránsito hacia el Welfare State, la "segunda modernidad" preconizará, en este sentido, la reconfiguración de la política en términos distintos a los linderos delineados por el capital a aquella categoría estatal, tradicionalmente dibujada a partir del Estado-nación (Beck, 1998). La cartografía política, se dirá, ha sido superada por la geo-economía global (Ohmae, 1997). 
De tal suerte podría afirmarse que con la globalización se presenta un fenómeno de subordinación de la polis frente al oikos, es decir, de lo público a lo privado: se trata, en suma, del predomino del globalismo ${ }^{8}$ como baluarte del capital.

Se apunta, en este marco, que la autonomía de los estados se ve comprometida debido a que éstos encuentran cada vez mayor dificultad para cumplir con sus agendas internas sin la cooperación de otros actores, políticos y económicos, que se ubican por encima y más allá de las fronteras del Estado (Held y McGrew, 2002 en Gilbert, 2008).

En este mismo tenor, Zygmunt Bauman (2001: 86,87) afirmará que "los estados están dispuestos a renunciar a ejercer una soberanía política, económica y militar plena, a cambio de la cooperación política o la integración económica".

Para Susan Strange (2003), el declive de la autoridad estatal se ve reflejada en una difusión creciente de la autoridad, así como en una creciente asimetría entre los Estados mayores con poder estructural y los Estados más débiles que no lo tienen.

La búsqueda de soluciones locales, en términos del Estado nación, a problemas globales se torna, de tal talante, un esfuerzo fútil que orilla a la "hiperlocalización" de la política y a la "hiperventilación" de lo político.

La jurisdicción estatal al verse limitada en la posibilidad de dar respuesta a las demandas sociales en ámbitos que se estiman de capital importancia para los ciudadanos (Bobbio, 2003) y que en otros tiempos la colocaban como protagonista en el escenario de los intercambios, queda reducida a la realización de acciones de gestoría del capital ${ }^{9}$ o a la mera administración de servicios públicos esenciales.

\footnotetext{
${ }^{8}$ Ulrich Beck hace una distinción entre los términos globalidad, globalización y globalismo. Asimismo, toma distancia de este último por considerarlo la defensa a ultranza de una "metafísica del mercado global", es decir, el discurso ideológico justificatorio del neoliberalismo: "Por globalismo entiendo la concepción según la cual el mercado mundial desaloja o sustituye el quehacer político; es decir, la ideología del dominio del mercado mundial o la ideología del liberalismo. Ésta procede de manera monocausal y economicista y reduce la pluridimensionalidad de la globalización a una sola dimensión, la económica, dimensión que considera asimismo de manera lineal, y pone sobre el tapete (cuando, y si es que, lo hace) todas las dimensiones -las globalizaciones ecológica, cultural, política y social- sólo para destacar el presunto predominio del sistema de mercado mundial [...] El núcleo ideológico del globalismo reside más bien en que da al traste con una distinción fundamental de la primera modernidad, a saber, la existente entre política y economía". Por otra parte, la globalidad denotará "el hecho de que [...] nada de cuanto ocurra en nuestro planeta podrá ser un suceso localmente delimitado, sino que todos los descubrimientos, victorias y catástrofes afectarán a todo el mundo y que todos deberemos reorientar y reorganizar nuestras vidas y quehaceres, así como nuestras organizaciones e instituciones, a lo largo del eje local-global" (Beck, 1998: 27, 28).

9 Para Susan Strange "lo que cuenta en las relaciones entre Estados ya no es la competencia por el territorio o por el control sobre los recursos naturales del territorio, sino la competencia por las cuotas de mercado mundiales" (Strange, 2003).
} 
En este sentido, Bauman (2001: 92) no duda en afirmar que "los Estados débiles son justamente lo que necesita el Nuevo Orden Mundial para sustentarse y reproducirse. Es fácil reducir un cuasi Estado débil a la función (útil) de una estación de policía local, capaz de asegurar el mínimo de orden necesario para los negocios, pero sin despertar temores de que pueda limitar la libertad de las compañías globales".

Este contexto, en el que las decisiones que afectan a las personas muy a menudo se toman fuera de los confines estatales y por lo tanto devienen en decisiones ajenas al ciudadano, si no es que, en ocasiones contrarias al mismo, produce una sensación de depreciación de lo político pues se pone en entredicho la legitimidad de los gobiernos y el valor de la democracia.

De esta manera, la democracia como forma de gobierno se ve reducida a una suerte de deus ex machina que coloca en el proscenio político a personajes que, aunque caracterizados para la representación, carecen muy frecuentemente del talento histriónico, es decir de la competencia, jurisdicción o simplemente disposición, para atender las demandas de quienes, en un mero ejercicio procedimental y costumbrista, los eligieron con la esperanza de ver satisfechas sus necesidades o, en términos de Bauman (2001), ver transformada "la contingencia en determinación [y] el azar en regularidad". ${ }^{10}$

Es en este sentido que, "en su significado más profundo, la globalización expresa el carácter indeterminado, ingobernable y autopropulsado de los asuntos mundiales; la ausencia de un centro, una oficina de control, un directorio, una agencia general" (Bauman, 2001:80).

Esta falta de un centro de poder global que regule la actividad de los entes económicos transnacionales no sólo refleja el desvanecimiento de la distinción fundamental, otrora existente, entre política y economía, sino que refuerza el predominio del sistema de libre mercado mundial sobre el quehacer político nacional (Beck, 1998).

En otras palabras, al caracterizar a la globalización como un fenómeno esencialmente económico, producido por la expansión de los mercados a nivel planetario, se ha abonado el terreno para que las ideas retomadas del liberalismo clásico se consolidaran como el paradigma dominante en la última década del siglo XX y lo que va del XXI.

\footnotetext{
${ }^{10}$ Para Zygmunt Bauman "una persona racional ya no confiará en el Estado para que le proporcione todo lo que necesita en caso de desempleo, enfermedad o ancianidad, ni para asegurar a sus hijos una salud decente ni educación. Sobre todo, una persona racional no esperará a que el Estado proteja a sus súbditos de golpes que parecen caer al azar del juego pobremente entendido y descontrolado de las fuerzas globales. Así que hay una nueva pero profundamente arraigada sensación de que, por mucho que uno sepa cómo debería ser una buena sociedad, no encontrará ningún organismo capaz ni deseoso de hacer realidad anhelos populares como éstos" (Bauman, 2005: 99).
} 


\section{GLOBALIZACIÓN Y NEOLIBERALISMO}

La creciente importancia que fue adquiriendo, a partir de 1960, el mercado de capitales capaz de evadir las regulaciones nacionales destinadas a proteger las monedas locales de la especulación y la devaluación condujo al llamado "resurgimiento de los mercados financieros globales" (Helleiner, 1994 en Babb, 2001:4) y al colapso, en 1971, del sistema Bretton Woods sustento del modelo de desarrollo de corte Keynesiano (Babb, 2001:4). ${ }^{11}$

El neoliberalismo, que rescata los postulados de Adam Smith y David Ricardo, no hizo caso omiso de las inmejorables condiciones que ofrecía el proceso de globalización para fortalecer y expandir a nivel mundial la doctrina económica aplicada en el Reino Unido de la Gran Bretaña y los Estados Unidos de América desde principios de los años ochenta del siglo pasado.

En este sentido, Steger y Roy (2011:30) señalan que los defensores del neoliberalismo,

"desde el punto de vista ideológico, [entrelazaron] sus postulados con referencias a la interdependencia económica global, anclada en los principios del capitalismo de libre mercado: la mundialización del comercio y los mercados financieros, el flujo internacional de productos, servicios y mano de obra, las corporaciones multinacionales, [...] etc.".

Para Michel Chossudovsky (2003: 108), en este orden de ideas, los avances tecnológicos de largo alcance constituyeron:

"un impulso vital para el proceso de reubicación industrial: los centros de toma de decisiones corporativas están en contacto instantáneo con puntos manufactureros y plantas de ensamble alrededor del mundo. Las innovaciones de alta tecnología de los ochenta y noventa representan, en el capitalismo global, un poderoso instrumento de control y supervisión empresarial operando a nivel mundial. La empresa global minimiza los costos de mano de obra a nivel mundial gracias a su habilidad para vincularse a (o subcontratar) puntos de producción con mano de obra barata alrededor del mundo [...]".

El libre mercado y la ventaja comparativa se constituían, en este tenor, en los mecanismos por excelencia que habrían de poner fin a las recurrentes crisis económicas que, de acuerdo con los neoliberales, ponían en entredicho las medidas tomadas durante "la edad de

\footnotetext{
11 "El sistema Bretton Woods fue creado en 1945 con el propósito de mantener la estabilidad monetaria internacional, lo que Keynes consideraba una pre-condición fundamental para la conducción de políticas macroeconómicas nacionales efectivas (Simmons 1999: 37-38). Al cobijo de Bretton Woods se instituyó un fuerte sistema de controles de capital, se establecieron tipos de cambio fijos y se promovió el equilibrio monetario internacional mediante prudentes inyecciones de efectivo hechas por el FMI. Con tales medidas fue posible para los gobiernos desarrollar políticas económicas relativamente independientes diseñadas para promover el pleno empleo sin provocar altos niveles de inflación" (Babb, 2001:4).
} 
oro del capitalismo controlado" y que cuestionaban el sustento teórico del crecimiento económico de los "Treinta gloriosos" (1945-1975). ${ }^{12}$

De tal manera, el incremento de los precios del petróleo, en la década de los setenta, que provocó una grave recesión en la economía mundial y la llamada crisis de la deuda, de principios de los años ochenta, abonaron al resurgimiento de la creencia en que "la magia del mercado" podría regular la economía de manera eficiente. El neoliberalismo se convirtió rápidamente en la ortodoxia económica en el Norte y fue exportada al Sur global mediante políticas de ayuda y medidas formuladas para hacer frente a dicha crisis (Simon, 2008: 86, 87).

En este sentido es que se afirma que "existe una relación estrecha, casi "simbiótica", entre las políticas de manejo de la deuda y las reformas macroeconómicas" (Chossudovsky, 2003:50)

Las Ilamadas políticas de ayuda, se puede advertir, no fueron más que el azadón mediante el cual los organismos financieros internacionales removieron tierra blanda y plantaron la semilla del neoliberalismo en América Latina a fin de conducir a la región a parámetros de mercado.

\section{EL SELLO NEOLIBERAL EN LA GLOBALIZACIÓN: LOS PROGRAMAS DE AJUSTE ESTRUCTURAL}

El magro crecimiento de las economías nacionales y las altas tasas inflacionarias se le adjudicaban al "exceso" de regulación estatal y al "inmenso" gasto público que, de conformidad con la doctrina económica en boga, sofocaba la natural tendencia de los mercados para regular la generación y distribución de la riqueza.

Steger y Roy $(2011: 27,28)$ apuntan que:

\footnotetext{
12 Steger y Roy señalan que "La aplicación política de las ideas keynesianas inspiró lo que algunos economistas dieron en llamar <<la edad de oro del capitalismo controlado>>, un período que se extendió de 1945 a 1975. Los programas americanos del New Deal y The Great Society, encabezados por los presidentes Roosevelt y Lyndon B. Johnson respectivamente, el tan admirado modelo sueco de socialdemocracia o la versión británica del <<Estado del bienestar»> lanzado en 1945 reflejaban un alto grado de consenso político entre los países occidentales, hasta el punto de que algún entendido llegó a proclamar <<la muerte de las ideologías >>. Los gobiernos nacionales controlaban los flujos monetarios que entraban y salían de sus territorios. Gracias al alto nivel de impuestos con que se gravaba a los grupos más ricos y a las empresas más rentables, se consiguió expandir el Estado del bienestar. Al subir los salarios y ampliarse los servicios sociales, los trabajadores de los países ricos del Norte consiguieron convertirse en clase media." (Steger, Roy, 2011: 23).

Por su parte Bruno Palier apunta que "El crecimiento económico de los $<<$ Treinta gloriosos $>>$ (19451975) reposa en gran parte sobre las beneficiosas interacciones entre desarrollo de la industria de bienes estandarizados, de gran consumo, el consumo de masa y la generalización de la protección social" (Esping-Andersen, Palier, 2010: 8,9).
} 
"una vez aceptada mayoritariamente esta premisa, el siguiente paso, en buena lógica, fue admitir que los países pertenecientes al Ilamado Sur global no alcanzarían un adecuado desarrollo económico si se mantenían esos mismos factores. Y así nació una agenda de desarrollo global de carácter neoliberal basada esencialmente en los llamados "programas de ajuste estructural" y en acuerdos internacionales de libre comercio [...], a partir de entonces si los países en desarrollo altamente endeudados querían obtener los préstamos que tanto necesitaban, tenían que aceptar la agenda neoliberal que les imponían instituciones tan poderosas como el Fondo Monetario Internacional o el Banco Mundial".

Surge así, en la década de los ochenta del siglo pasado, el denominado "Consenso de Washington" término con el que se hacía referencia a la serie de medidas económicas promovidas por las instituciones financieras internacionales sitas en la capital de la Unión Americana y que para los siguientes decenios se convertiría en el marco que definiría los lineamientos de desarrollo económico a nivel mundial. ${ }^{13}$

Las medidas económicas promovidas por dicho Consenso se sustentaron en los llamados programas de ajuste estructural que atendían a dos fases de aplicación: medidas estabilizadoras, en un primer momento, y de ajuste, en una segunda etapa.

Las medidas estabilizadoras eran inmediatas y estaban confeccionadas para atender los efectos de la crisis, así como para proveer una base sobre la cual se pudieran ejecutar las reformas estructurales.

En esta primera fase se tenían contempladas la austeridad presupuestaria, la liberalización de precios y la devaluación de la moneda. La austeridad presupuestaria se enfocaba en el recorte de programas sociales y en la reducción de la nómina pública. La liberalización de precios consistía en la eliminación de los controles a éstos y la desaparición de

\footnotetext{
13 "Con frecuencia interpretamos el <<Consenso de Washington>> como sinónimo de neoliberalismo. La expresión, acuñada en la década de 1980 por el economista liberal John Williamson, se refiere al paquete de medidas económicas (entendidas en términos de <<mínimo común denominador >>) que el Fondo Monetario Internacional (FMI), el Banco Mundial y otras instituciones económicas y think-tanks con sede en Washington recomendaron a la mayoría de los países latinoamericanos. En la década de 1990 se convirtió en el marco que definiría el <<adecuado>> desarrollo económico a nivel mundial. Para obtener los créditos que tanto necesitaban y conseguir que se ejecutara la reestructuración de los programas de devolución de deuda, a los países del llamado Sur global se les exigió adherirse al Consenso de Washington y adoptar las medidas necesarias para atenerse al siguiente plan: 1) Garantía de disciplina fiscal y freno al déficit presupuestario, 2) Reducción del gasto público, [...] 3) Reforma fiscal, a fin de crear un sistema de amplia base y de cumplimiento eficaz, 4) Liberalización financiera, aceptando las tasas de interés que determinara el mercado, 5) Tasas de intercambio competitivas para ayudar al crecimiento de la exportación, 6) Liberalización comercial, que suponía la abolición de licencias de importación, así como la reducción de aranceles, 7) Promoción de la inversión extranjera directa, 8) Privatización de las empresas estatales, a fin de lograr una gestión eficaz y mejores rendimientos, 9) Desregulación de la economía, 10) Protección de los derechos de propiedad”, (Steger, Roy, 2011: 42, 43).
} 
subsidios. La devaluación de la moneda se estipulaba como requisito indispensable para favorecer las exportaciones.

Las medidas de ajuste generalmente se implementaban en una segunda etapa y estaban dirigidas a promover la reestructuración económica. La liberalización del comercio y financiera, el fomento a las exportaciones, la privatización de las empresas públicas, la desregulación económica y la reforma fiscal formaban parte del paquete enfocado en esa reforma estructural.

La liberalización comercial consistía en la eliminación de cuotas de importación y la reducción de barreras arancelarias protectoras a fin de alentar una economía de exportación.

La liberalización financiera (desregulación del sistema bancario) buscaba que la política monetaria dejara de ser responsabilidad del banco central a fin de que las tasas de interés fueran determinadas por el libre mercado. Asimismo, se perseguían la desregulación y/o privatización de la banca de desarrollo y comercial, promoviéndose la entrada de capital extranjero en el sector bancario nacional. La autonomía del banco central, en este marco, se estimaba de suma importancia.

La venta de empresas públicas tenía como objetivo reducir la injerencia del Estado en la economía, a la vez que se promovía que el capital privado tanto nacional como extranjero tuviera participación en empresas rentables de sectores estratégicos (petróleo, gas, energía eléctrica y telecomunicaciones).

La reforma fiscal introducía modificaciones a la estructura de impuestos directos, perseguía la ampliación de la base contributiva y promovía, como parte de la desregulación económica, la generación de exenciones fiscales a empresas y corporaciones como mecanismo para atraer la inversión extranjera directa (Simon, 2008; Chossudovsky, 2003; Steger, Roy, 2011).

La adopción de estas medidas se convirtió, para los países del tercer mundo, en condición para la obtención de los préstamos de los organismos financieros internacionales y los recursos de las agencias bilaterales de desarrollo.

En este sentido, sostienen Steger y Roy (2011) que desde la perspectiva del FMI o el Banco Mundial para lograr un crecimiento económico sostenido y salvar de la pobreza a millones de personas era necesario reconducir a los países endeudados hacia parámetros de mercado. A tal fin, vincularon su asistencia económica con programas de ajuste anclados en recetas de talla única. 
No obstante, señalará Chossudovsky (2003), en el nuevo orden comercial (que surgió de las conclusiones de la Ronda de Uruguay en Marrakech en 1994) las relaciones entre las instituciones sitas en Washington y los gobiernos nacionales han sido redefinidas. La imposición de las políticas prescritas por el FMI-Banco Mundial ya no depende solamente de los convenios de préstamo ad hoc a nivel nacional (que no son documentos legalmente obligatorios). En lo sucesivo, muchas de las cláusulas del programa de ajuste estructural (por ejemplo, la liberalización del comercio, la privatización y el régimen de inversión externa) estarán insertadas permanentemente en los artículos de convenio de la Organización Mundial del Comercio (OMC). Estos artículos sientan las bases para "vigilar" a los países (y para imponer "condicionantes") de acuerdo con el derecho internacional.

Es así que el neoliberalismo como paquete de medidas económicas, mediante la triada privatización, liberalización y desregulación, se impuso alrededor del orbe no sólo como una forma de encauzar las políticas económicas de gobierno sino también como ideología dominante. ${ }^{14}$

De esta manera, en la década de los noventa, a la condicionalidad económica le siguió la condicionalidad política enfocada en la promoción del denominado "buen gobierno". ${ }^{15} \mathrm{El}$ impulso a la democracia como mejor forma de gobierno, el respeto a los derechos humanos y la rendición de cuentas se enmarcan dentro de este contexto.

En esta misma tónica se dio un giro a los programas de ajuste estructural para darles un cariz ético mediante la incorporación de estrategias de combate-reducción-alivio de la pobreza. ${ }^{16}$

\footnotetext{
${ }^{14}$ Para Steger y Roy el neoliberalismo es un término amplio que hace referencia al modelo económico predominante desde la década de 1980, basado en el ideal del liberalismo clásico según el cual el mercado se regula a sí mismo, no obstante, ponen énfasis en la distinción de lo que ellos denominan sus tres manifestaciones (interconectadas entre sí), a saber: Neoliberalismo como ideología, neoliberalismo como modo de gobierno y neoliberalismo como paquete de medidas económicas. Desde el punto de vista ideológico, los neoliberales entrelazan sus postulados con referencias a la interdependencia económica global. En la segunda dimensión del neoliberalismo, retomando a Michel Foucault, apuntan que la mentalidad de gobierno neoliberal se basa en valores empresariales como la competitividad, el interés y la descentralización, valorando positivamente el fortalecimiento del poder individual y la disolución del poder central del Estado en unidades locales más pequeñas. En último término, la manifestación del neoliberalismo como conjunto concreto de medidas económicas se expresa en la fórmula desregulación-liberalización-privatización, (Steger, Roy, 2011: 29-34).

15 "Las condicionalidades político-económicas asociadas a los programas de ajuste estructural representaron una invasión sin precedente al hasta ahora sacrosanto derecho de los Estados soberanos a determinar sus propias políticas" (Bracking, 1999; Mohan et. al, 1999 citados en Simon, 2008: 89,90).

${ }^{16}$ Chossudovsky (2003: 37) apuntará que el dogma neoliberal crea su propio "contraparadigma" que da forma a un discurso altamente moral y ético, centrado en el "desarrollo sustentable" y el "alivio de la pobreza". Este enfoque ético y sus subcategorías (mitigar la pobreza, cuestiones relativas al género, la
} 
Desde los años 1999-2000 el FMI y el Banco Mundial adoptaron las "estrategias de reducción de la pobreza" como continuación de los programas de ajuste estructural que a diferencia de éstos priorizaban el gasto anti-pobreza y debían incorporar la participación de la sociedad mediante procesos de consulta. No obstante, la condicionalidad político-económica del buen gobierno y de la eficiencia macroeconómica, vinculada a los préstamos o a la condonación de deuda a los países pobres altamente endeudados, continuó presente en dichas estrategias (Simon, 2008).

En este orden de ideas, aunque el combate a la pobreza se convirtió en requisito de los acuerdos para préstamos, dicho combate "bajo el dominio de las instituciones de Bretton Woods" se ha promovido recortando los presupuestos de los programas sociales y canalizando el gasto sobre una base selectiva mediante programas focalizados destinados a grupos vulnerables, combinados con la recuperación de costos y la privatización de servicios (Chossudovsky, 2003).

\section{LA REINVENCIÓN DE LOS SISTEMAS DE SALUd EN EL MARCO DE LOS PROGRAMAS DE AJUSTE ESTRUCTURAL}

La reducción del gasto destinado a los programas sociales, promovida al amparo del ajuste estructural, ha conducido a la continua privatización de servicios otrora considerados esenciales para el bienestar de la colectividad y por lo tanto de interés público y responsabilidad social. La incursión de la iniciativa privada en los sistemas de pensiones ${ }^{17}$ y en la prestación de servicios de salud, en este marco, responde a los patrones confeccionados por el Consenso de Washington. ${ }^{18}$

igualdad, etc.) presta un "rostro humano" a las instituciones de Bretton Woods y presenta un compromiso ficticio con el cambio social.

${ }^{17}$ Retomamos el caso de las pensiones dado que las reformas a los sistemas de salud se dieron de manera paralela a las promovidas por los organismos financieros internacionales para la seguridad social. No debemos olvidar que en muchos países el ámbito de la atención a la salud formaba parte del campo más amplio de la seguridad social (baluarte del Estado de bienestar) que también incluía los sistemas de pensiones que no pocas veces, como en el caso de México, financiaban los servicios de salud de buena parte de la población.

${ }^{18}$ Mitchell Orenstein apunta que la causa de la privatización de las pensiones fue priorizada por el Banco Mundial, con el apoyo estratégico del FMI y de USAID, la agencia de desarrollo de E.U.A. Señala que mientras estas instituciones asumían el liderazgo a la hora de promover la sustitución de la provisión de pensiones pública por la comercial, los think tanks neoliberales y los grandes bancos desempeñaron un papel de apoyo, contribuyendo a cubrir el coste de los seminarios, estudios y documentos de posición y llevando a cabo un importante esfuerzo de promoción una vez que la legislación era inminente (Orenstein en Blackburn, 2010:17). 
En 1994, el Banco Mundial emitió un informe denominado "Envejecimiento sin crisis: políticas para la protección de los ancianos y la promoción del crecimiento" donde se señalaban las causas que guiaban la intención de reforma de los sistemas de pensiones, consistente en el reemplazo de los sistemas públicos por planes individuales operados por instituciones del sector financiero.

Cabe destacar, como señala Blackburn (2010: 18) que "el auténtico interés del Banco Mundial se centraba [...] en los Estados de renta media de Europa del Este y América Latina y en los Estados desarrollados con un sistema público de pensiones $<<$ predominante >".

Respecto al ámbito de la salud, en el Informe sobre el desarrollo mundial 1993, elaborado por el Banco Mundial y subtitulado "Invertir en Salud", se planteaba una reformulación de las políticas de salud, enfocada nuevamente en los países en desarrollo y los otrora comunistas.

Dicha reformulación se proponía en tres vertientes, en primer término, se señalaba la necesidad de promover un ambiente económico que permitiera a los hogares mejorar su propia salud. En segundo lugar, se buscaba el redireccionamiento del gasto público hacia acciones "costo-efectivas", como la vacunación, el control y tratamiento de enfermedades infecciosas en vez de destinar los recursos a la atención médica de especialidad.

Finalmente, la tercera vertiente proponía el fomento de mayor diversidad y competencia en la prestación de servicios de salud, mediante la descentralización de la atención pública, la promoción de prácticas competitivas y la incursión de organizaciones no gubernamentales e instituciones privadas, así como la regulación del mercado de seguros (Banco Mundial, 1993).

De manera paralela, el Banco Mundial fortaleció su programa de préstamos destinados a apoyar las reformas de los sistemas de salud. Para finales de la década de 1990 se había convertido en la agencia internacional que más fondos destinaba a los países en vías de desarrollo para ese rubro. En 1999, según precios de 1996, el Banco Mundial había concedido préstamos por un valor total de 16,800 millones de dólares (Govindaraj, et.al., 2000 en Homedes, Ugalde, 2005: 210).

Para el caso de la reforma de los sistemas de salud en Latinoamérica, en el marco de la Reunión Especial de Ministros de Salud de América Latina y el Caribe sobre la Reforma del Sector Salud, celebrada en Washington D.C. en septiembre de 1995 y organizada por el Banco Mundial, el Banco Interamericano de Desarrollo (BID), la Organización de Estados Americanos (OEA), la Agencia de los Estados Unidos para el Desarrollo Internacional (USAID), la Comisión 
Económica para América Latina y el Caribe (CEPAL), la Organización Panamericana de la Salud (OPS), el Fondo de Naciones Unidas para la Infancia (UNICEF) y el Fondo de Población de Naciones Unidas (UNFPA), se presentó el documento llamado "Pluralismo estructurado: hacia un modelo innovador para la reforma de los sistemas de salud en América Latina", esta propuesta, cabe destacar, fue elaborada para el Departamento Técnico para América Latina y el Caribe del Banco Mundial y pretendía constituirse en el modelo a seguir en la inminente reestructuración de los sistemas de salud en la región (Londoño, Frenk, 1997).

El pluralismo estructurado, para Londoño y Frenk (1997: 324, 325), consistía en "la búsqueda de un punto medio entre los arreglos polares. [...] del monopolio en el sector público y la atomización en el sector privado", de tal manera que dentro de este esquema la prestación de servicios se convierte en ámbito de competencia de instituciones tanto públicas como privadas.

No obstante, es menester señalar que aún antes de que emergiera en el seno del Banco Mundial la propuesta del pluralismo estructurado, "Chile, que había tenido un sistema nacional de salud con cobertura universal y de acceso gratuito entre 1952 y 1981, fue el primer país latinoamericano en aplicar una reforma neoliberal a principios de la década de 1980. La dictadura fragmentó el sistema [...] y creó aseguradoras privadas denominadas Institutos de Salud Previsional (ISAPRE). También descentralizó la atención primaria y hospitalaria mediante su transferencia a las municipalidades y a las áreas de salud, respectivamente, y en 1986 estableció cuotas de recuperación en el sector público" (Homedes, Ugalde, 2005: 211).

Asimismo, siguiendo las recomendaciones del Banco Mundial, en 1993 Colombia a partir de la Ley 100 inició el proceso de reforma de su sistema de salud teniendo como guía el modelo de competencia regulada o pluralismo estructurado que introducía elementos como el aseguramiento universal en salud, las administradoras de servicios y un plan obligatorio de salud (Homedes, Ugalde, 2005: 211).

Cabe destacar que México no fue la excepción pues en las reformas promovidas para el sector salud el Banco Mundial ha tenido un papel destacado. Digno de mención, en este aspecto, es el documento intitulado "Mexico. Health System Reform-IMSS" de 1998, mediante el cual se establece el tipo de asistencia con la que ese organismo multilateral apoyaría "el diseño e implementación de cambios determinantes en la política del sector salud en México, principalmente mediante reformas en el Instituto Mexicano del Seguro Social (IMSS)" (Banco 
Mundial, 1998), encaminadas a la generación de incentivos para la participación de la iniciativa privada en el sector. ${ }^{19}$

En nuestro país, desde principios de los años ochenta, los consecutivos gobiernos de la República se han destacado por la entusiasta aquiescencia con la que han incorporado a la vida nacional las recetas prescritas por las renovadas instituciones de Bretton Woods.

Entusiasmo nada inverosímil de advertir dada la recomposición de la clase política gobernante, formada en consistencia con los principios de la economía neoclásica en boga, que aceptó de buen grado participar en el desmantelamiento del estado "benefactor" para favorecer la "revolución del libre mercado".

De tal suerte, se ha llegado a afirmar que las reformas neoliberales en el país más que una imposición externa, fueron alegremente abrazadas por un grupo de tecnócratas educados en universidades americanas (Babb, 2001: 171-186).

En este sentido se señala que, aunque las presiones externas claramente tuvieron que ver con la implementación de ciertas políticas económicas a partir de 1982, un factor clave fue la presencia de una importante y poderosa cohorte de economistas formados en Estados Unidos dentro del gobierno mexicano, quienes fueron capaces de aprovechar las presiones externas para desarticular el régimen desarrollista a partir de normas transnacionales de legitimación (Babb, 2001: 183, 186).

En el ámbito de la salud, la renovación de la clase política ha conducido a una reconfiguración paulatina del sector sustentada en un discurso que subraya el tránsito de una lógica política a una racionalidad técnica en cuanto al proceso de toma de decisiones se refiere (Frenk, et. al., 2003).

No obstante, ese aparente tránsito de lo político a lo técnico ha favorecido la puesta en marcha de una serie de procesos que responden a una visión "eficientista" de la función pública.

Esto es, en el marco de la "nueva gestión o gerencia pública" (sic) el ciudadano, dotado de derechos, se convierte en un "cliente" con requerimientos que la ley de la oferta y la demanda deberá satisfacer y en el que "los empleados del Estado ya no se [considerarán]

\footnotetext{
${ }^{19}$ The reform program for the period 1998-2000 to be supported by the loan would follow a two-pronged approach: (a) developing and implementing health insurance financing reforms and the necessary regulatory framework through (i) separating financing from provision of services, (ii) increasing consumer choice and extending coverage, and (iii) developing and implementing purchasing mechanisms; and (b) institutional strengthening of IMSS through (i) changing its corporate structure and (ii) strengthening its health care delivery network. Bank assistance would consist of this adjustment operation to help finance the costs of the reform and of a parallel Technical Assistance Loan (TAL), (World Bank, 1998).
} 
garantes de un <<bien público>> definido en términos cualitativos, sino participantes interesados y responsables del mercado" (Steger, Roy, 2011: 32).

La reconfiguración del sector salud debe analizarse desde esa óptica. No es casual que los mayores cambios introducidos desde principios de la década de 1980 hayan atendido a recomendaciones de organismos que han promovido, desde un nivel supranacional, principios que giran en torno a una mentalidad de gobierno "empresarial" ad hoc con la lógica de mercado también impulsada desde las trincheras de esas instituciones y fielmente respaldada por una "nueva generación de tecno-políticos" (Babb, 2001) encumbrados en las más altas esferas del poder quienes desde aquella época comparten, literal y metafóricamente hablando, el mismo idioma que aquellos que determinan extraterritorialmente lo que más conviene para el equilibrio macroeconómico de las naciones y el libre juego de las fuerzas del mercado.

De tal suerte, la descentralización de los servicios de salud, el establecimiento de cuotas de recuperación, la definición de paquetes esenciales de beneficios, la competencia estructurada, el aseguramiento médico universal y la integración funcional del sistema son premisas que se inspiran en valores extraídos del mundo de los negocios, como la productividad, la eficacia, la competencia, el rendimiento y la ventaja comparativa y que conducen, en el marco del ajuste estructural, al gradual debilitamiento de la intervención del Estado en los ámbitos en los que su participación no se estima conveniente y que a la larga conducen a que los individuos se den a la tarea de buscar de manera biográfica solución a problemas socialmente determinados (Bauman, 2011).

Dan cuenta de ello los recortes presupuestales al gasto social y el redireccionamiento de los recursos públicos hacia acciones "costo-efectivas".

Las cuotas de recuperación introducidas por los procesos de descentralización, por ejemplo, se convertirían en un elemento de inequidad que reduciría el acceso de la población con menos recursos a los servicios de salud, aun cuando los promotores de la descentralización argumentaban que ésta al acercar los servicios a la gente promovería mejores condiciones de atención ante las demandas generadas localmente.

El establecimiento de un paquete básico o esencial de servicios, por otro lado, limitaría el derecho constitucional a la protección de la salud con base en un número bien definido de "intervenciones" a las que el individuo ciudadanizado ${ }^{20}$ tendría derecho a recibir.

20 La formulación de un paquete de intervenciones esenciales, de acuerdo con Julio Frenk, es una
expresión del principio de ciudadanía dado que constituyen el núcleo de la universalidad, es decir, el 
Mientras que el aseguramiento médico universal y la integración funcional tenderían a redefinir la naturaleza del sector al promover un sistema pluralista sustentado en la competencia estructurada.

La reconfiguración del sector se puede decir, en este tenor, ha respondido a criterios encaminados a hacer transitar el derecho de protección a la salud de compromiso social a atribución personal en el marco de una lógica individualista pro-mercado que apunta hacia el financiamiento público de un número bien delimitado de servicios y la provisión privada de éstos, así como de los que no estén considerados dentro de dicho financiamiento, en un afán de convertir el ámbito de la salud en un bien económico susceptible de crear riqueza.

\section{BIBLIOGRAFÍA}

ABRANTES, R.; Salubristas y Neosalubristas en la Reforma del Estado. Grupos de interés en México e instituciones públicas de salud, 1982-2000, México, El Colegio de Michoacán, 2010.

ALBERT, M.; Capitalismo contra capitalismo, Argentina, Paidós, 1997.

ARES DE PARGA, R.; La Descentralización Financiera. En: DE LA FUENTE, R.; LÓPEZ-BÁRCENA, J.; Federalismo y Salud en México, Primeros Alcances de la Reforma de 1995, México, UNAMDIANA, 2001.

BABB, S.; Managing Mexico: Economists from Nationalism to Neoliberalism, USA, Priceton University Press, 2001.

BANCO MUNDIAL, Informe sobre el desarrollo mundial, 1993. Invertir en salud, Washington, D.C.: Banco Mundial, 1993.

BARBA, C.; La reforma del sistema de salud mexicano: eludiendo la universalización del derecho a la salud. En: RAMÍREZ, B.; HAM, R.; Encrucijadas, prospectivas y propuestas sobre la seguridad social en México, México, UNAM-Colegio de la Frontera Norte, 2012.

BAUMAN, Z.; Daños Colaterales. Desigualdades sociales en la era global, México, Fondo de Cultura Económica, 2011. Identidad, Buenos Aires, Losada, 2005.

La globalización. Consecuencias humanas, México, Fondo de Cultura Económica, 2001. 2008. Tiempos líquidos. Vivir en una época de incertidumbre, México, CNCA/Tusquets Editores,

BECK, U.; ¿Qué es la globalización? Falacias del globalismo, respuestas a la globalización, Barcelona, Paidós, 1998.

conjunto de intervenciones a las que toda persona debe tener acceso, independientemente de su capacidad financiera o situación laboral (Frenk, et.al. en Solís-Soberón, Villagómez, 1999: 94). 
BECK, U.; BECK-GERNSHEIM, E.; La individualización. El individualismo institucionalizado y sus consecuencias sociales y políticas, Barcelona, Paidós, 2003.

BOBBIO, N.; El futuro de la democracia, México, Fondo de Cultura Económica, 2003.

BURKI, SJ.; et. al., Beyond the Center: Decentralizing the State, Washington D.C., World Bank, 1999.

CABRERO, E.; MARTÍNEZ-VAZQUEZ, J.; Assignment of Spending Responsibilities and Service Delivery. En: GIUGALE, M.; WEBB, S.; Achievements and Challenges of Fiscal Decentralization. Lessons from Mexico, Washington D.C., Banco Mundial, 2000.

CHOSSUDOVSKY, M.; Globalización de la pobreza y nuevo orden mundial, México, Siglo XXI, 2003.

DESAI, V.; POTTER, R.; Globalization, employment and development. En: DESAI, V.; POTTER, R.; The Companion to Development Studies, Reino Unido, Hodder Education, Segunda Edición, 2008.

DE STEFFANO, M.; Organización y Competencia de las Autoridades Sanitarias. En: DE LA FUENTE R, LÓPEZ-BÁRCENA J, Federalismo y Salud en México, Primeros Alcances de la Reforma de 1995, México, UNAM-DIANA, 2001.

ESPING-ANDERSEN, G.; PALIER, B.; Los tres grandes retos del Estado del bienestar, España, Editorial Ariel, 2010.

FRENK, J.; et. al.; Economía y salud: propuestas para el avance del sistema de salud en México. Informe final, México, FUNSALUD, 1994.

Evidence-based health policy: three generations of reform in Mexico, The Lancet, 362: 1667-1671, November 15, 2003.

La Seguridad Social en Salud: Perspectivas para la Reforma. En: SOLíS-SOBERÓN, F.; VILLAGÓMEZ, A.; La Seguridad Social en México, México, FCE-CIDE, 1999.

Salud: Un diagnóstico, Nexos, México, 2004, 26 (317): 71-78.

FRENK, J.; GÓMEZ-DANTÉS, O.; El sistema de salud de México, México, Nostra Ediciones, 2008.

GERSHBERG, A.; JACOBS, M.; Decentralization and Recentralization: Lessons from the Social Sectors in Mexico and Nicaragua, Office of the Chief Economist Working paper \# 379, Washington D.C., Inter-American Development Bank, 1998.

GIDDENS, A.; Consecuencias de la Modernidad, Madrid, Alianza Editorial, 2004. 2008.

Un mundo desbocado. Los efectos de la globalización en nuestras vidas, México, Taurus,

The new international division of labor. En: DESAI, V.; POTTER, R.; The Companion to Development Studies, Reino Unido, Hodder Education, Segunda Edición, 2008.

GONZÁLEZ-BLOCK, M.; et.al.; Health Services Decentralization in Mexico: Formulation, Implementation, and Results of Policy, Health Policy and Planning, 1989, 4 (4):301-315. 
HELD, D.; La democracia y el orden global. Del Estado moderno al gobierno cosmopolita, Barcelona, Paidós, 1997.

HERNÁNDEZ-TRILLO, F.; Seguridad social universal. Retos para su implementación. En: México, México, CIDE, 2012.

LEVY, S.; Good Intentions, Bad Outcomes. Social Policy, Informality, and Economic Growth in Mexico, Washington D.C., Brookings Institution Press, 2008. 2012.

Seguridad social universal: Un camino para México, Nexos, Núm. 419, México, noviembre

LONDOÑO, J.; FRENK, J.; Pluralismo estructurado: hacia un modelo innovador para la reforma de los sistemas de salud en América Latina. En: FRENK, J. (ed); Observatorio de la Salud. Necesidades, servicios, políticas, México, FUNSALUD, 1997.

LÓPEZ-ARELLANO, O.; BLANCO-GIL, J.; La polarización de la política de salud en México, Cad. Saúde Publica, Río de Janeiro, 17 (1): 43-54, jan-fev, 2001.

LÓPEZ-ARELLANO, O.; et.al.; La universalización del acceso a la atención médica y a la salud desde la salud colectiva y los derechos en Organización Panamericana de la Salud (OPS)-Organización Mundial de la Salud (OMS), Cobertura Universal en Salud: Lecciones Internacionales Aprendidas y Elementos para su Consolidación en México, México, OPS, 2013.

LÓPEZ-BÁRCENA, J.; REAL-MATA, T.; Avances de la Descentralización de los Servicios de Salud en México, 1995-1999. En: DE LA FUENTE, R.; LÓPEZ-BÁRCENA, J.; Federalismo y Salud en México, Primeros Alcances de la Reforma de 1995, México, UNAM-DIANA, 2001.

MERINO, G.; Descentralización del Sistema de Salud en el Contexto del Federalismo. En: KNAUL, F.; NIGENDA, G.; (Ed.); Caleidoscopio, México, FUNSALUD, 2003.

NARRO, J.; Seguridad social en México, algunas propuestas. En: RAMÍREZ, B.; HAM, R.; Encrucijadas, prospectivas y propuestas sobre la seguridad social en México, México, UNAMColegio de la Frontera Norte, 2012.

OHMAE, K.; El fin del estado-nación, Santiago, Editorial Andrés Bello, 1997.

POTTER, R.; Global convergence, divergence and development. En: DESAl, V.; POTTER, R.; The Companion to Development Studies, Reino Unido, Hodder Education, Segunda Edición, 2008.

RITZER, G.; The MacDonalization of Society, California, New Century, 2004.

SEGALL, M.; District Health Systems in a Neoliberal World: A Review of Five Key Policy Areas, International Journal of Health Planning and Management, 2003, 18 (Supl 1): S5-S26.

SIMON, D.; Neoliberalism, structural adjustment and poverty reduction strategies. En: DESAI, V.; POTTER, R.; The Companion to Development Studies, Reino Unido, Hodder Education, Segunda Edición, 2008.

SOBERÓN. G.; El cambio estructural en la salud, Salud Pública de México, 29:127-140, 1987. 
STEGER, M.; Roy, R.; Neoliberalismo Una Breve Introducción, España, Alianza editorial, 2011.

STRANGE, S.; La retirada del Estado: la difusión del poder en la economía mundial, traducción Josep Ibáñez, Barcelona, Icaria, Intermón Oxfam, 2003.

VALENZUELA-FEIJÓO, JC.; El modelo neoliberal, contenido y alternativas, Investigación Económica, Revista de la Facultad de Economía de la UNAM, Enero-Marzo 1995, No. 211.

WORLD BANK; Decentralized service delivery for the poor, Vol. 1, World Bank, México, 2006. Decentralized service delivery for the poor, Vol. 2, World Bank, México, 2006. 1998.

Mexico-Health System Reform-IMSS Adjustment Loan, Washington, D.C., World Bank,

ZABLUDOVSKY, G.; Globalización: Un concepto polivalente. En: PÉREZ-FERNÁNDEZ DEL CASTILLO, G.; LEÓN Y RAMÍREZm J.C.; (Coordinadores), El léxico de la política en la globalización. Nuevas realidades, viejos referentes, México, Miguel Ángel Porrúa/Facultad de Ciencias Políticas y Sociales, UNAM, 2008.

ZOLO, D.; Globalización. Un mapa de los problemas, España, Ediciones Mensajero, 2006.

Trabalho enviado em 01 de junho de 2017.

Aceito em 28 de julho de 2017. 